\title{
STUDI EKSPERIMENTAL PENGARUH VARIASI SUDUT BLADE ARC TERHADAP PERFORMA SAVONIUS HORIZONTAL AXIS WATER TURBINE TIPE L PADA ALIRAN DALAM PIPA
}

\author{
Muhammad Ilham Nadhief ${ }^{1}$, Syamsul Hadi ${ }^{1}$, Dominicus Danardono Dwi Prija Tjahjana ${ }^{1}$ \\ ${ }^{\mathbf{1}}$ Teknik Mesin - Universitas Sebelas Maret \\ e-mail address : ilham_nadhief@yahoo.com
}

Keywords:

Turbin air sumbu horisontal, Savonius, Sudut blade arc, koefisien daya, Pico hydro.

\begin{abstract}
:
Air merupakan energi baru dan terbarukan pengganti energi fosil yang dapat digunakan untuk memenuhi kebutuhan listrik masa depan karena jumlahnya yang melimpah. Turbin air savonius horizontal axis water turbine (HAWT) mampu beroperasi pada kecepatan putar rendah sehinga cocok untuk pembangkit listrik tenaga air menggunakan metode rain water harvesting $(\mathrm{RWH})$. Namun, turbin ini memiliki koefisien daya dan torsi yang rendah. Penelitian prototipe rotor turbin tipe $\mathrm{U}$ dengan variasi jumlah sudu, sudut kelengkungan telah dilakukan sebelumnya untuk meningkatkan kinerja turbin ini. Dalam makalah ini, dibahas proses perancangan dan pengujian terhadap sebuah prototipe rotor turbin tipe L dengan 3 variasi sudut blade arc. Variasi sudut blade arc yang diuji adalah $120^{\circ}, 135^{\circ}$ dan $150^{\circ}$. Melalui penelitian ini, diketahui tipe turbin yang optimal jika dianalisa dari power output, TSR, dan power coefficient yang dihasilkan oleh turbin. Turbin tipe L dengan sudut blade arc $135^{\circ}$ memiliki power coefficient paling tinggi sebesar $27 \%$ dengan TSR sebesar 1,320 dibandingkan turbin dengan sudut blade arc $120^{\circ}$ dan $150^{\circ}$.
\end{abstract}

\section{PENDAHULUAN}

Penggunaan sumber energi fosil untuk pembangkit listrik dari tahun ke tahun terus meningkat yang diakibatkan oleh pertumbuhan populasi terus mengalami peningkatan. Salah satu sumber energi yang banyak digunakan dalam pembangkit listrik tenaga uap adalah batubara. Hal ini membuat konsumsi batubara dalam negeri sebesar 70 juta ton $(85,37 \%)$ digunakan oleh PLTU dan sisanya digunakan oleh industri logam, industri kertas dan industri lainnya[1]. Potensi tenaga air sebagai salah satu sumber energi terbarukan untuk Pembangkit Listrik Tenaga Air (PLTA) dan Pembangkit Listrik Tenaga Mini/Mikro Hidro (PLTMH) tersebar di Indonesia dengan total perkiraan mencapai 75.000 MW, sementara pemanfaatannya masih sekitar $11 \%$ dari total potensi [2].

Metode Rain Water Harvesting (RWH) merupakan metode untuk menampung air hujan dalam sebuah tangki sebelum digunakan kembali untuk tujuan tertentu. Eksperimen Rain Water Harvesting menggunakan tipe turbin Savonius singlestage pernah dilakukan. Hasilnya, sistem turbin Savonius memiliki kinerja yang baik dengan menghasilkan tegangan dan kuat arus yang konstan [3]. Turbin Savonius merupakan vertical axis wind turbine (VAWT) tipe drag, memiliki kontruksi sederhana, mampu beroperasi pada kecepatan rendah namun memiliki efisiensi yang rendah [4]. Namun pada penelitian ini, diubah menjadi turbin Savonius Horizontal Axis Water Turbine (HAWT). Savonius tipe sudu semi-cylindrical dengan jumlah sudu 3 memiliki tip speed ratio (TSR) paling tinggi dan performa paling baik dibandingkan lainnya [5].

Selain itu, beberapa penelitian menunjukkan bahwa modifikasi parameter sudu seperti overlap ratio, aspect ratio, bentuk sudu dan sebagainya dapat memengaruhi performa turbin [6]. Salah satunya penelitian yang dilakukan oleh Soelaiman, dkk yang membandingkan bentuk sudu Savonius tipe U dan tipe L menunjukkan bahwa sudu Savonius tipe L menghasilkan torsi yang paling baik dibandingkan dengan sudu Savonius tipe U[7].

Penelitian tentang pengaruh depth to width ratio telah dilakukan oleh S. Hadi dkk. Hasilnya sudu dengan depth to width ratio 0.29 memiliki performa terbaik dengan TSR 0.61 karena blade dengan 0.29 memiliki volume tampung yang lebih besar sehingga mampu menghasilkan torsi dan kecepatan putar yang lebih besar pula [8]. Sukanta Roy dkk, membandingkan variasi sudut blade arc pada blade Savonius tipe L dari $\Phi=90^{\circ}-165^{\circ}$ dengan interval $15^{\circ}$. Dan hasilnya menunjukkan bahwa blade tipe $\mathrm{L}$ dengan blade arc $\Phi=135^{\circ}$ mampu meningkatkan performa sebesar 36\% [9].

Dalam penelitian ini akan dilakukan pengujian pada turbin Savonius tipe L dengan variasi sudut blade arc. Pengujian dilakukan dengan mengamati pengaruh variasi sudut blade arc pada sudu turbin air savonius terhadap daya listrik, power coefficient dan TSR yang dihasilkan sehingga dapat diketahui turbin savonius tipe $\mathrm{L}$ dengan sudut blade arc yang paling optimal. 


\section{METODOLOGI PENELITIAN}

Pada penelitian ini, desain turbin dan apparatus test mengacu pada penelitian sebelumnya [3], [6], [8], [9]. Dengan ketinggian head $1.8 \mathrm{~m}$ dan $2 \mathrm{~m}$ serta menggunakan apparatus test seperti gambar 1 dibawah ini.

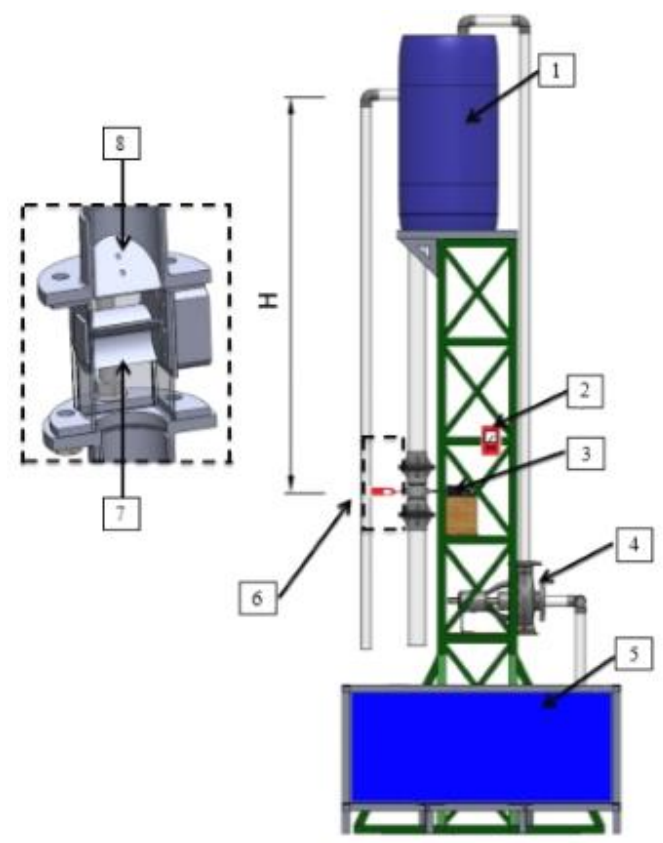

Gambar 1. Apparatus Test

Keterangan :

1. Tangki atas

5. Tangki bawah

2. Multitester

6. Tachometer

3. Alternator

7. Turbin

4. Pompa Sentrifugal

8. Deflekctor

Turbin yang digunakan berdiameter $82 \mathrm{~mm}$, aspect ratio $H / D=1$ dan endplate ratio 1,1 . Kemudian tebal turbin adalah $2 \mathrm{~mm}$ berbahan $A B S$ (Acrylonitrile Butediene Styrene) dan diproduksi menggunakan mesin $3 D$ printing. Turbin memiliki arc radius yang diimprovisasi dari penelitian Roy, dkk [9] dengan $\mathrm{S} 2=16,8 \mathrm{~mm}$ dan $\mathrm{S} 1=20 \mathrm{~mm}$, blade gap (a) $0 \%$ serta memiliki variasi sudut blade $\operatorname{arc}(\Phi)$ $120^{\circ}, 135^{\circ}$ dan $150^{\circ}$. Desain turbin savonius L dapat dilihat pada Gambar 1.

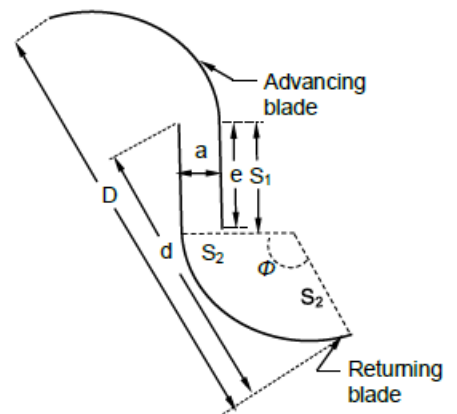

Gambar 2. Desain Turbin Savonius tipe L

Penelitian ini dilakukan dengan memvariasikan 4 debit aliran air pada tiap variasi turbin[10]. Dengan debit mulai dari $5,66 \times 10^{-3} \mathrm{~m}^{3} / \mathrm{s} ; 7,97 \times 10^{-3} \mathrm{~m}^{3} / \mathrm{s}$; $9,73 \times 10^{-3} \mathrm{~m}^{3} / \mathrm{s}$; dan $11,61 \times 10^{-3} \mathrm{~m}^{3} / \mathrm{s}$ yang diatur dengan variasi bukaan katub pada pipa. Gambar 3 merupakan variasi turbin dengan sudut blade arc:

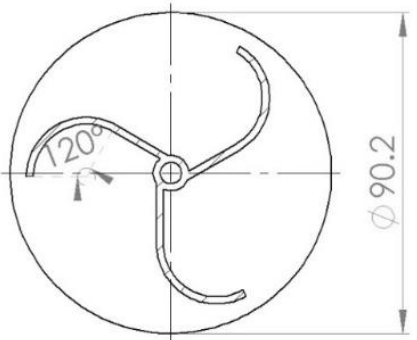

(a) Sudut Blade Arc $120^{\circ}$

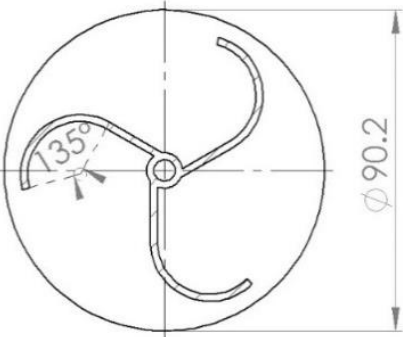

(b) Sudut Blade Arc $135^{\circ}$

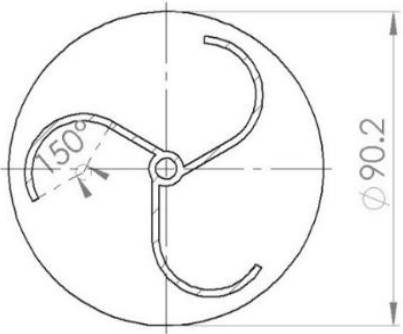

(c) Sudut Blade Arc $150^{\circ}$

Gambar 3. Variasi Turbin

Data penelitian yang diamati pada penelitian ini antara lain debit, rpm, voltase dan kuat arus. Tegangan dan kuat arus diamati menggunakan multimeter, kemudian rotasi putaran turbin diamati menggunakan tachometer.

\section{HASIL DAN PEMBAHASAN}

Daya fluida merupakan fungsi dari densitas air, gaya gravitasi, debit fluida dan ketinggian jatuhnya air. Sehingga debit fluida yang mengalir berpengaruh terhadap daya fluida yang dihasilkan. Daya fluida yang masuk mengalir pada turbin akan meningkat seiring dengan bertambahnya debit fluida yang mengalir seperti yang dapat dilihat pada Gambar 4 . Daya yang dihasilkan ketika debit $5,66 \times 10^{-3} \mathrm{~m}^{3} / \mathrm{s}$ sebesar 99,601 watt. Kemudian meningkat menjadi 140,090 watt ketika debit ditingkatkan menjadi $7,97 \times 10^{-3} \mathrm{~m}^{3} / \mathrm{s}$. Saat debit sebesar $9,73 \times 10^{-3} \mathrm{~m}^{3} / \mathrm{s}$, menghasilkan daya 171,206 watt dan semakin meningkat saat debit $11,61 \times 10^{-3} \mathrm{~m}^{3} / \mathrm{s}$ dengan daya sebesar 227,048 watt. 


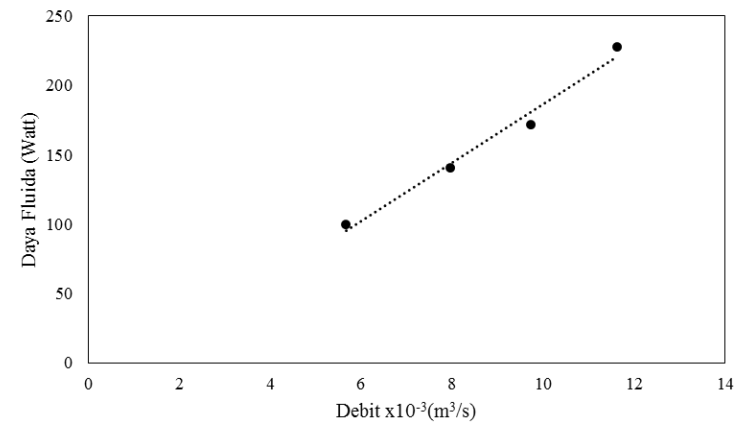

Gambar 4. Grafik Pengaruh Debit Air terhadap Daya Fluida

Daya yang dihasilkan tiap variasi turbin dapat dilihat pada Gambar 5. Daya yang dihasilkan oleh turbin dengan sudut blade arc $135^{\circ}$ lebih tinggi jika dibandingkan turbin dengan sudut blade arc $120^{\circ}$ dan turbin dengan sudut blade arc $150^{\circ}$. Peningkatan debit dapat meningkatkan daya generator yang, seperti yang terlihat pada Gambar 4 dimana terjadi kenaikan daya generator pada debit $7,97 \times 10^{-3} \mathrm{~m}^{3} / \mathrm{s}$ dibanding dengan debit $5,66 \times 10^{-3} \mathrm{~m}^{3} / \mathrm{s}$ dan seterusnya.

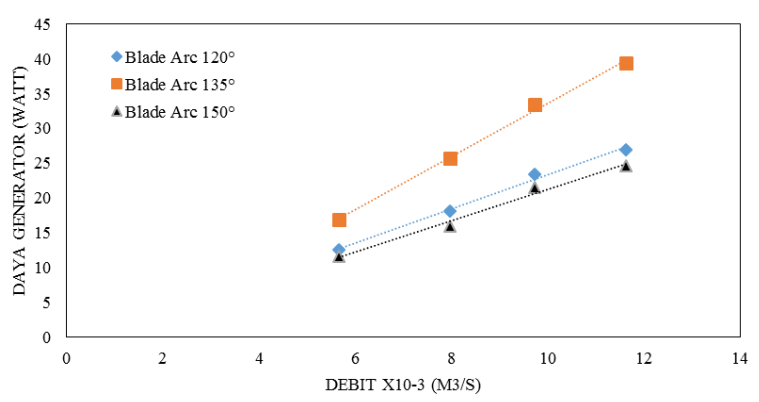

Gambar 5. Grafik Pengaruh Debit Air terhadap Daya Generator

Turbin dengan sudut blade arc $135^{\circ}$ mampu menghasilkan daya generator yang paling baik daripada turbin lainnya. Karena turbin dengan sudut blade arc $135^{\circ}$ memiliki bentuk geometri yang paling optimal dibanding turbin lainnya. Memiliki panjang blade arc yang paling optimal sehingga mampu memiliki gaya putar yang lebih besar untuk melawan torsi negatif yang terjadi.

Tip speed ratio (TSR) merupakan perbandingan antara kecepatan ujung turbin (angular) terhadap kecepatan fluida yang melewati turbin. Sedangkan power coefficient $(C p)$ adalah perbandingan antara energi fluida yang dapat di ekstrak atau ditangkap oleh turbin dengan energi keseluruhan yang ada dalam fluida. Nilai TSR berkisar antara 0-4[11]. Cp biasanya digunakan untuk menilai performa dari suatu turbin. Nilai $T S R$ dan $C p$ pada masing-masing turbin tiap variasi debit dapat dilihat di Gambar 6.

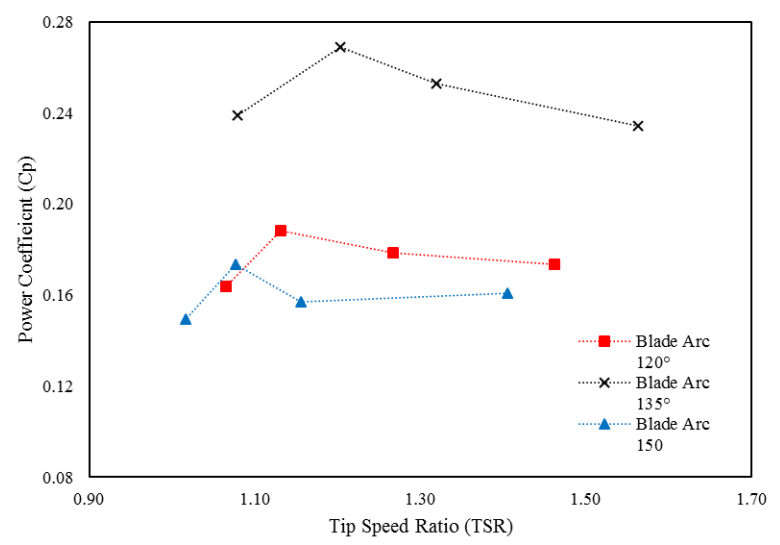

Gambar 6. Grafik Pengaruh Tip Speed Ratio (TSR) Terhadap Power Coefficient (Cp)

Pada saat debit $5,66 \times 10^{-3} \mathrm{~m}^{3} / \mathrm{s}$ turbin dengan sudut blade arc $120^{\circ}$ memiliki nilai TSR dan $C p$ sebesar 1,462 dan 0,174. Turbin dengan sudut blade arc $135^{\circ}$ mengalami peningkatan TSR dan $C p$ menjadi 1,563 dan 0,235. Kemudian turbin dengan sudut blade arc $150^{\circ}$ mengalami penurunan TSR dan Cp menjadi 1,405 dan 0,161 .

Nilai TSR mengalami penurunan pada saat variasi debit $7,965 \times 10^{-3} \mathrm{~m}^{3} / \mathrm{s}$ jika dibandingkan saat debit $5,66 \times 10^{-3} \mathrm{~m}^{3} / \mathrm{s}$, namun nilai $C p$ mengalami peningkatan. Pada debit ini nilai TSR dan $C p$ turbin dengan sudut blade arc $120^{\circ}$ sebesar 1,267 dan 0,179. Ketika turbin dengan sudut blade arc $135^{\circ}$ terjadi peningkatan TSR dan $C p$ menjadi 1,320 dan 0,254. Kemudian turbin dengan sudut blade arc $150^{\circ}$ mengalami penurunan TSR dan $C p$ menjadi sebesar 1,156 dan 0,158 .

Ketika debit $9,73 \times 10^{-3} \mathrm{~m}^{3} / \mathrm{s}$, nilai $T S R$ mengalami penurunan dibandingkan variasi debit sebelumnya, namun nilai $C p$ mengalami peningkatan. Turbin dengan sudut blade arc $120^{\circ}$ memiliki nilai TSR dan $C p$ sebesar 1,131 dan 0,189. Kemudian turbin dengan sudut blade arc $135^{\circ}$ memiliki nilai $T S R$ dan $C p$ sebesar 1,204 dan 0,270 Sedangkan nilai TSR dan $C p$ turbin dengan sudut blade arc $150^{\circ}$ sebesar 1,077 dan 0,174.

Kemudian kembali terjadi penurunan TSR dan $C p$ saat debit sebesar $11,61 \times 10^{-3} \mathrm{~m}^{3} / \mathrm{s}$. Turbin dengan sudut blade arc $120^{\circ}$ hanya mampu menghasilkan nilai TSR dan $C p$ masing-masing sebesar 1,065 dan 0,164 . Turbin dengan sudut blade arc $135^{\circ}$ menghasilkan TSR dan Cp sebesar 1,079 dan 0,240. Dan turbin dengan sudut blade arc $150^{\circ}$ hanya menghasilkan TSR dan $C p$ sebesar 1,016 dan 0,150.

Turbin dengan sudut blade arc $120^{\circ}$ memiliki $C p$ maksimum saat $T S R$ sebesar 1,131 dengan nilai $C p$ sebesar 0,189. Kemudian untuk turbin dengan sudut blade arc $135^{\circ}$ memiliki $C p$ maksimum sebesar 0,270 yang terjadi ketika TSR sebesar 1,204. Sedangkan $C p$ maksimum turbin dengan sudut blade arc $150^{\circ}$ terjadi saat nilai TSR sebesar 1,077 dengan nilai $C p$ sebesar 0,174 . 


\section{KESIMPULAN}

Setelah melakukan eksperimen dan analisa perhitungan data, maka dapat disimpulkan bahwa :

1. Besar sudut blade arc $135^{\circ}$ memiliki daya yang paling besar kemudian daya akan menurun ketika turbin dengan sudut blade arc $120^{\circ}$ dan blade arc $150^{\circ}$ yang dikarenakan adanya penurunan putaran turbin.

2. Turbin dengan sudut blade arc $135^{\circ}$ mampu menghasilkan daya generator yang paling tinggi untuk semua variasi debit, yaitu masing-masing sebesar 16,90 watt, 25,71 watt, 33,38 watt dan 39,35 watt.

\section{REFERENSI}

[1] Sekretariat Jenderal Dewan Energi Nasional, Outlook Energi Indonesia 2016. Jakarta, 2016.

[2] Kementrian ESDM, Data Kementrian ESDM. Jakarta, 2016.

[3] N. Rosmin, A. Safwan, and A. Hatib, "Experimental study for the single-stage and double-stage two-bladed Savonius microsized turbine for rain water harvesting ( RWH ) system," Energy Procedia, vol. 68, pp. 274-281, 2015.

[4] N. H. Mahmoud, A. A. El-Haroun, and E. Wahba, "An experimental study on improvement of Savonius rotor performance," Alexandria Eng. J., vol. 51, no. 1, pp. 19-25, 2012.

[5] F. Wenehenubun, A. Saputra, and H. Sutanto, "An experimental study on the performance of Savonius wind turbines related with the number of blades," Energy Procedia, vol. 68, pp. 297-304, 2015.

[6] V. J. Modi and M. S. U. K. Fernando, "On the Performance of the Savonius Wind Turbine," Sol. Energy Eng., vol. 111, no. February 1989, pp. 71-81, 2015.

[7] T. A. F. Soelaiman, N. P. Tandian, and N. Rosidin, "Perancangan, Pembuatan dan Pengujian Prototipe SKEA Menggunakan Rotor Savonius dan Windside untuk Penerangan Jalan Tol," Ris. Unggulan ITB, 2007.

[8] S. Hadi, R. J. Apdila, and A. H. Purwono, "Performance of The Drag Type of Horizontal Axis Water Turbine ( HAWT ) as Effect of Depth to Width Ratio of Blade," AIP Conf. Proc. 1788, vol. 030004, pp. 1-5, 2017.

[9] S. Roy and U. K. Saha, "Numerical Investigation To Assess An Optimal Blade Profile For The Drag Based Vertical Axis Wind Turbine," Proc. ASME 2013, pp. 1-9, 2013.
[10] I. Hamzah, A. Prasetyo, D. D. D. P. Tjahjana, and S. Hadi, "Effect of Blades Number to Performance of Savonius Water Turbine in Water Pipe," AIP Conf. Proc. 1931, vol. 030046, pp. 1-5, 2018.

[11] J. Chen, H. X. Yang, C. P. Liu, C. H. Lau, and M. Lo, "A novel vertical axis water turbine for power generation from water pipelines," Energy, vol. 54, pp. 184-193, 2013. 